Check for updates

Cite this: RSC Adv., 2019, 9, 8426

\title{
Development of a nano-QSPR model to predict band gaps of spherical metal oxide nanoparticles $\uparrow$
}

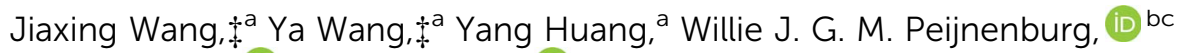 \\ Jingwen Chen $\mathbb{D}^{a}$ and Xuehua Li $(\mathbb{D}$ *a
}

Antibacterial activities and cytotoxicity of metal oxide nanoparticles are determined by their special band structures, which also influence their potential ecological risks. Traditional experimental determination of the band gap is time-consuming, while the accuracy of theoretical computation depends on the selected algorithm, for which higher precision algorithms, being more expensive, can give a more accurate band gap. Therefore, in this study, a quantitative structure-property relationship (QSPR) model, highlighting the influence of crystalline type and material size, was developed to predict the band gap of metal oxide nanoparticles rapidly and accurately. The structural descriptors for metal oxide nanoparticles were generated via quantum chemistry computations, among which heat of formation and beta angle of the unit cell were the most important parameters influencing band gaps. The developed model shows great robustness and predictive ability $\left(R^{2}=0.848, \mathrm{RMSE}=0.378 \mathrm{eV}, \mathrm{RMSE}_{\mathrm{CV}}=0.478 \mathrm{eV}, Q_{\mathrm{EXT}}{ }^{2}=\right.$ $0.814, \mathrm{RMSE}_{\mathrm{P}}=0.408 \mathrm{eV}$ ). The current study can assist in screening the ecological risks of existing metal oxide nanoparticles and may act as a reference for newly designed materials.

Received 13th December 2018

Accepted 6th March 2019

DOI: $10.1039 / \mathrm{c} 8 \mathrm{ra10226k}$

rsc.li/rsc-advances more attention. ${ }^{2}$ One of the main mechanisms of oxidative damage caused by MONs is the overlap of conduction band energy $\left(E_{\mathrm{C}}\right)$ levels with the cellular redox potential. The overlap of $E_{\mathrm{C}}$ with the redox potential leads to the transfer of electrons from reductive substances, which then generate reactive oxygen species (ROS) which could eventually damage cells. ${ }^{3-5}$ Therefore, the $E_{\mathrm{C}}$ value is a meaningful parameter for the assessment of the ecological risks of MONs. $E_{\mathrm{C}}$ can be calculated by means of eqn (1): $E_{\mathrm{C}}$ refers to the conduction band energy; $E_{\mathrm{g}}$ is the band gap energy and $\chi_{\text {oxide }}$ is the absolute electronegativity of the metal oxide. ${ }^{6}$

$$
E_{\mathrm{c}}=\chi_{\text {oxide }}+0.5 E_{\mathrm{g}}
$$

The absolute electronegativity can be calculated by a set of equations reported by Portier et al. ${ }^{7}$ Values of the band gaps of MONs can be obtained from experimental determination and from estimation.

The experimental determination of band gaps requires diffuse reflectance UV-vis spectroscopic analysis, which can accurately measure the band gaps of MONs. However, considering the increase of emerging MONs both in amount and types as well as taking into account that band gaps of MONs vary when crystalline types, sizes and shapes are different, ${ }^{8}$ experimental determinations of band gaps are inefficient and cannot provide any guide at all for the design of novel MONs that are safe with regard to their ecological impacts.

Estimation methods were proposed, including theoretical computation and empirical equation to obtain band gaps

\footnotetext{
${ }^{a}$ Key Laboratory of Industrial Ecology and Environmental Engineering (MOE), School of Environmental Science and Technology, Dalian University of Technology, Linggong Road 2, Dalian 116024, China. E-mail: lixuehua@dlut.edu.cn

${ }^{b}$ Institute of Environmental Sciences, Leiden University, 2300 RA Leiden, The Netherlands

${ }^{C}$ National Institute of Public Health and the Environment, Center for the Safety of Substances and Products, 3720 BA Bilthoven, The Netherlands

$\dagger$ Electronic supplementary information (ESI) available. See DOI: $10.1039 / \mathrm{c} 8 \mathrm{ra} 10226 \mathrm{k}$

$\ddagger$ These authors contributed equally to the paper.
} 
efficiently and conveniently. As for theoretical computation, its inaccuracy is the main obstacle which undermines its authorization and application domain. For example, the band gaps of solids could be underestimated with an accuracy of $30-100 \%$ in a typical density functional theory calculation. ${ }^{9}$ Building a cluster of unit cells was tried, ${ }^{10}$ but computation for a cluster commensurate with real material requires vast investment of computational resources. As for empirical estimation, Portier et al., ${ }^{11}$ demonstrated the correlation between band gap and thermodynamic properties, and put forward an empirical equation to estimate band gap of bulk metal oxides by using enthalpies of formation (eqn (2)).

$$
\begin{gathered}
E_{\mathrm{g}}=A \mathrm{e}^{0.34 E_{\Delta H}} \\
E_{\Delta H}=-2 \times \Delta H_{\mathrm{f}}^{\circ} \times 2.612 \times 10^{19} /(N \times \mathrm{ne})
\end{gathered}
$$

In the eqn (3), $\Delta H_{\mathrm{f}}^{\circ}$ refers to the standard enthalpy of formation of the oxide in cal $\mathrm{mol}^{-1}$ and the coefficient $A$ is determined by cation ion of the oxide, $N$ is Avogadro's number, ne refers to the number of valence electron. For s-block, p-block, d-block and f-block of metal elements, the reported $A$ values are $0.80,1.35,1.00$ and 0.80 respectively. ${ }^{11}$ Using this empirical equation, the band gaps of binary oxides can be calculated very quickly. But this equation ignores the effects of size differences. Therefore, it is required to develop a prediction method to obtain the band gap of MONs with different crystalline type and particle size accurately and efficiently.

Quantitative structure-property relationships (QSPRs) have been used to predict various properties of chemicals. ${ }^{12,13}$ QSPRs can be applied fast, they are low-cost and efficient compared with other methods. For MONs, several QSPRs models were reported to predict photo-induced toxicity of MONs, including toxicity of MONs to E. coli and to human keratinocyte cells as well as the cell uptake rate of MONs. ${ }^{14-17}$ Wyrzykowska et al. developed a nano-QSPR model to predict the zeta potential of MONs in $\mathrm{KCl}$ aqueous solution of MONs. ${ }^{18}$

In this study, we developed a nano-QSPR model, considering different crystalline types and sizes, to predict band gaps of MONs. Besides, band gaps were also calculated by two other estimation methods to compare the predictive ability of different methods. From a wider perspective, this study could help screen the potential ecological risk of MONs and provide reference for newly designed MONs.

\section{Methods}

\subsection{Data set for band gaps}

Experimental band gaps of MONs were obtained by collection from literature ${ }^{3,19-50}$ and by experimental determination.

To control variables that influence band gaps of MONs as much as possible and to ensure the consistency of collected band gaps, a qualified data point from literature must meet the following demands: size of material is in the nanometer scale; particles must be spherical or approximate a spherical shape; particles have a single chemical makeup without any chemical modification on the surface; characterizations including X-ray diffraction, which verifies the crystalline structure of MONs, and UV-vis spectroscopic analysis are required.

Seven kinds of MONs (5 nm anatase- $\mathrm{TiO}_{2}, 25 \mathrm{~nm}$ anatase$\mathrm{TiO}_{2}, 40 \mathrm{~nm}$ anatase- $\mathrm{TiO}_{2}, 100 \mathrm{~nm}$ anatase- $\mathrm{TiO}_{2}, 40 \mathrm{~nm}$ rutile$\mathrm{TiO}_{2}, 100 \mathrm{~nm}$ rutile- $\mathrm{TiO}_{2}$ and $50 \mathrm{~nm} \mathrm{ZnO}$ ) bought from Aladdin (http://www.aladdin-e.com/) were prepared for UV-vis spectroscopic analysis using UV-550 spectrophotometer produced by JASCO Corporation. To minimize possible errors, each determination for each material was repeated three times and the eventual outcome is the arithmetic mean of parallel experiments. The raw data of UV-vis spectroscopic analysis were transformed according to the Kubelka-Munk equation. ${ }^{51}$

The total data set of band gaps of MONs was split randomly into a training set and a validation set with a ratio of $3: 1(30: 10)$.

\subsection{Date pre-processing}

Previous studies indicated that the band gap of relatively large particles (size $>10 \mathrm{~nm}$ ) is not affected by size whereas the quantum confinement effect only occurs when the size of nanoparticle is smaller than approximately $10 \mathrm{~nm}$, consequently leading to a larger value of band gap. ${ }^{.2,53}$ Therefore, the value of the band gaps of materials with size smaller than $10 \mathrm{~nm}$ was used directly. In case of material with a size larger than $10 \mathrm{~nm}$, the average size and the average band gap were calculated and included in either the training set or the validation set.

\subsection{Descriptors}

The descriptors used to develop the nano-QSPR were derived from theoretical calculation, as well as from literature and experimental characterization. (1) Theoretical descriptors were calculated by using the Vienna $A b$ initio Simulation Package (VASP) 5.4.1 (ref. 54) and MOPAC2016 (ref. 55) (2) reported descriptors of MONs in literatures, such as the ratio of metal atoms to oxygen atoms and weight of atoms, were included in this study, remaining to be selected further., ${ }^{4,56}$ (3) Experimental characterization outcomes such as size, crystalline type information and the number of unit cells contained by the material were included.

To consider the influence of crystalline types to band gaps of materials in calculation, input files should specify crystalline type, which must be consistent with corresponding band gap of every material. The XRD outcomes or joint committee powder diffraction standards (JCPDS) number was collected from the same literature from which the value of the band gap of MONs was collected. MDI JADE 5.0 (ref. 57) was utilized to analyze collected XRD patterns and to match the corresponding standard XRD cards, which could specify crystalline type. Based on the crystalline type information derived from standard cards, the corresponding crystalline file in common intermediate format (CIF) was obtained in FindIt ${ }^{58}$ before being transformed by Open Babel 2.4.1 (ref. 59) into standard input files. Single cell units were optimized by the general gradient approximate (GGA) of VASP before descriptor computation and the error of optimization for structure was verified to be within $5 \%$. Descriptors of VASP computation were obtained from POTCAR 
and OUTCAR after structure optimization. The PM7 method was used to generate various descriptors in MOPAC computation. In order to validate the acceptability of descriptors derived from the computation being based on single cell units, important descriptors selected in model were compared with their experimental values.

In order to ensure that the correlation between descriptors and band gaps is linear, several parameters were processed before they were suited as descriptor. Heat of formation of the unit cell, computed by MOPAC, was transformed according to a previously reported empirical equation. ${ }^{11}$ The reciprocal value of the squared diameter was processed as a descriptor according to the Brus equation (eqn (4)). ${ }^{52}$

$$
E_{\mathrm{g}}(R)=E_{\mathrm{g}}(R=\infty)+\frac{h^{2}}{8 R^{2}}\left[\frac{1}{m_{\mathrm{e}-}^{*}}+\frac{1}{m_{\mathrm{h}+}^{*}}\right]
$$

\subsection{QSPR modeling}

Partial least square (PLS) regression was utilized to develop the QSPR model. The SIMCA 13.0 software package was used to provide PLS as well as the subsequent analysis. ${ }^{60}$ The PLS approach was established around 1975 by Herman Wold for the modelling of complicated data sets. ${ }^{61}$ The basic principle of PLS could be interpreted as PLS being the combination of principal components analysis (PCA), correlation analysis (CA) and multiple linear regression (MLR). ${ }^{62}$ Unlike MLR, PLS can analyze data with strongly collinear, noisy and numerous $\mathrm{X}$ variables. ${ }^{63}$ In our study, the amount of descriptors is relatively large and the correlation between various descriptors is difficult to demonstrate. Therefore, PLS was used to develop this model.

A genetic algorithm (GA), developed by means of the $\mathrm{R}$ program, ${ }^{64}$ was used to select descriptors for developing prediction models. The number of descriptors in the model was further decreased by using a method reported in literature: ${ }^{.5}$ Based on the values of the variable influence for the projection (VIP), descriptors with lower VIP values were deleted from the model until the model shows best validation performance.

\subsection{Model characterization}

In order to ensure the reliability and predictive ability of the developed model, various analyses were done to characterize the performance of the model. The correlation coefficient $R^{2}$ between predicted and observed $E_{\mathrm{g}}$ and the root mean standard error of estimation ( $\mathrm{RMSE}_{\mathrm{E}}$ ) measure the fitting performance. The performance of internal validation could be indicated by the root mean standard error of cross validation $\left(\mathrm{RMSE}_{\mathrm{CV}}\right)$, which is based on the leave-one-out (LOO) test. As for external validation, the predictive power of the developed QSPR model was estimated by means of calculating the root mean standard error of prediction ( $\mathrm{RMSE}_{\mathrm{P}}$ ) and $Q_{\mathrm{EXT}}{ }^{2}$ defined by means of eqn (5), where $y_{i}$ and $\hat{y}_{i}$ are the measured and predicted value of $E_{\mathrm{g}}$ in the validation set, respectively; $\bar{y}_{i}$ is the average value of $E_{\mathrm{g}}$ for the training set. A value of $Q_{\mathrm{ExT}}{ }^{2}$ larger than 0.5 indicates a good predictive capability of the model and a value of $Q_{\mathrm{ExT}}{ }^{2}$ larger than 0.9 indicates excellent predictive ability.

$$
Q_{\mathrm{EXT}}{ }^{2}=1-\frac{\sum_{i=1}^{\text {test }}\left(y_{i}-\hat{y}_{i}\right)^{2}}{\sum_{i=1}^{\text {test }}\left(y_{i}-\bar{y}_{i}\right)^{2}}
$$

According to the OECD guideline, ${ }^{66}$ the applicability domain of the developed model was determined by the method reported by $\mathrm{K}$. Roy et al. ${ }^{67}$ Firstly, descriptors in training set were normalized. If all of the normalized descriptors for a material are larger than 3 , that material can be judged as an outlier. On the contrary, a material is treated as non-outlier if all of its normalized descriptors are smaller than 3. For a material who has some descriptors larger than 3 but the others not, it will be further investigated.

\section{Results and discussion}

\subsection{Data set of band gaps}

Through data collection, 91 values of band gaps of 22 different MONs were collected., ${ }^{3,19-50}$ Band gaps ranged from $1.85 \mathrm{eV}$ to $6.07 \mathrm{eV}$ with an average of $3.60 \mathrm{eV}$ and a standard deviation of $0.8 \mathrm{eV}$. The particles diameters ranged from $2.5 \mathrm{~nm}$ to $100 \mathrm{~nm}$ with an average of $26.0 \mathrm{~nm}$ and a standard deviation of $24.8 \mathrm{~nm}$. All collected data are shown in Table $\mathrm{S} 1 \dagger$ and the data set processed according to particles size for model development is displayed in Table 1.

The distribution of band gaps values for MON with multiple sizes was investigated in more detail. First of all, the arithmetic means and standard deviations of the band gaps were calculated: $\mathrm{CeO}_{2}(3.50 \pm 0.13 \mathrm{eV}), \mathrm{Cr}_{2} \mathrm{O}_{3}(3.82 \pm 0.24 \mathrm{eV}), \mathrm{Cu}_{2} \mathrm{O}(2.57 \pm 0.34$ $\mathrm{eV}), \mathrm{Fe}_{2} \mathrm{O}_{3}(2.38 \pm 0.33 \mathrm{eV}), \mathrm{Ga}_{2} \mathrm{O}_{3}(4.93 \pm 0.12 \mathrm{eV}), \mathrm{NiO}(3.43 \pm$ $0.19 \mathrm{eV}), \mathrm{SnO}_{2}(3.93 \pm 0.38 \mathrm{eV}), \mathrm{TiO}_{2}(3.25 \pm 0.03 \mathrm{eV}), \mathrm{ZnO}(3.25 \pm$ $0.08 \mathrm{eV})$. Fig. $1 \mathrm{a}$ and $\mathrm{b}$ show the distribution of band gaps of NiO and $\mathrm{SnO}_{2}$ respectively as a function of their squared diameter. It can be observed clearly from these plot that band gaps increase as size decreases to values below $10 \mathrm{~nm}$, indicating the occurrence of a quantum confinement effect around $10 \mathrm{~nm}$. However, ambiguity does exist. For example, band gaps increase was not observed for some particles smaller than $10 \mathrm{~nm}$. Besides, large variance of values of band gaps were observed, especially for $\mathrm{SnO}_{2}$ larger than $10 \mathrm{~nm}$. NiO with size of $10.1 \mathrm{~nm}$ and $12.4 \mathrm{~nm}$ were treated as two single points although their sizes are larger than $10 \mathrm{~nm}$ because they display significant difference from other data with size larger than $10 \mathrm{~nm}$. It is the same with $\mathrm{Cr}_{2} \mathrm{O}_{3}$. These phenomena might due to these materials are from different literatures, in which materials were synthesized by different methods in different conditions. These differences are hard to characterize because of limited information. Therefore, using the average value of data points with size larger than $10 \mathrm{~nm}$ could avoid this unexplainable difference and will minimize the uncertainty of data generated in different laboratories.

\subsection{Model development and evaluation}

Through PLS regression and descriptor selection, the model was obtained as given in eqn (6) (standard error of regression coefficients are listed in Table S5 $\dagger$ ). The coefficient of every descriptor in the reported equation is unscaled in order to be 
Table 1 Metal oxide nanoparticles and their structural descriptors ${ }^{a}$

\begin{tabular}{|c|c|c|c|c|c|c|c|c|c|c|c|}
\hline No. & Metal oxide & $a$ & $b$ & $c$ & $\alpha$ & $\beta$ & $\gamma$ & Size (nm) & $E_{\text {exp. }}(\mathrm{eV})$ & $E_{\text {pred. }}(\mathrm{eV})$ & Set \\
\hline 1 & $\mathrm{Al}_{2} \mathrm{O}_{3}$ & 4.81 & 4.81 & 13.12 & 90 & 90 & 120 & 76.0 & 5.97 & 5.74 & $\mathrm{~T}$ \\
\hline 2 & $\mathrm{CeO}_{2}$ & 5.46 & 5.46 & 5.46 & 90 & 90 & 90 & 12.0 & 3.39 & 3.74 & $\mathrm{~T}$ \\
\hline 4 & & & & & & & & 2.6 & 3.44 & 3.89 & $\mathrm{~T}$ \\
\hline 5 & $\mathrm{Cr}_{2} \mathrm{O}_{3}$ & 4.58 & 4.58 & 14.72 & 90 & 90 & 120 & 26.5 & 4.22 & 4.11 & $\mathrm{~T}$ \\
\hline 6 & & & & & & & & 38.2 & 3.70 & 4.11 & $\mathrm{~V}$ \\
\hline 9 & & & & & & & & 6.0 & 2.83 & 2.31 & $\mathrm{~V}$ \\
\hline 10 & & & & & & & & 20.0 & 2.04 & 2.28 & $\mathrm{~V}$ \\
\hline 11 & $\mathrm{Fe}_{2} \mathrm{O}_{3}$ & 4.74 & 4.74 & 13.49 & 90 & 90 & 120 & 100.0 & 2.38 & 2.96 & $\mathrm{~V}$ \\
\hline 12 & $\mathrm{Fe}_{3} \mathrm{O}_{4}$ & 8.04 & 8.04 & 8.04 & 90 & 90 & 90 & 12.0 & 1.85 & 2.61 & $\mathrm{~T}$ \\
\hline 13 & $\mathrm{Ga}_{2} \mathrm{O}_{3}$ & 12.50 & 3.10 & 5.92 & 90 & 103.7 & 90 & 65.0 & 4.85 & 4.81 & $\mathrm{~T}$ \\
\hline 14 & & & & & & & & 2.5 & 5.10 & 5.00 & $\mathrm{~T}$ \\
\hline 19 & $\mathrm{Mn}_{2} \mathrm{O}_{3}$ & 9.03 & 9.03 & 9.03 & 90 & 90 & 90 & 30.2 & 3.27 & 3.38 & $\mathrm{~T}$ \\
\hline 20 & $\mathrm{NiO}$ & 4.16 & 4.16 & 4.16 & 90 & 90 & 90 & 3.5 & 3.67 & 3.62 & $\mathrm{~T}$ \\
\hline 21 & & & & & & & & 4.6 & 3.63 & 3.58 & $\mathrm{~T}$ \\
\hline 22 & & & & & & & & 5.5 & 3.62 & 3.57 & $\mathrm{~V}$ \\
\hline 23 & & & & & & & & 10.1 & 3.62 & 3.54 & $\mathrm{~T}$ \\
\hline 24 & & & & & & & & 12.4 & 3.61 & 3.54 & $\mathrm{~T}$ \\
\hline 25 & & & & & & & & 22.0 & 3.27 & 3.53 & $\mathrm{~T}$ \\
\hline 26 & $\mathrm{Sb}_{2} \mathrm{O}_{3}$ & 5.18 & 16.61 & 5.51 & 90 & 90 & 90 & 11.8 & 4.49 & 4.77 & $\mathrm{~T}$ \\
\hline 27 & $\mathrm{SnO}_{2}$ & 4.83 & 4.83 & 3.24 & 90 & 90 & 90 & 4.5 & 4.20 & 3.80 & $\mathrm{~T}$ \\
\hline 28 & & & & & & & & 4.0 & 4.10 & 3.81 & $\mathrm{~V}$ \\
\hline 29 & & & & & & & & 5.0 & 4.21 & 3.79 & $\mathrm{~T}$ \\
\hline 30 & & & & & & & & 5.2 & 4.20 & 3.79 & $\mathrm{~V}$ \\
\hline 39 & $\mathrm{ZnO}$ & 3.29 & 3.29 & 5.31 & 90 & 90 & 120 & 35.0 & 3.24 & 2.62 & $\mathrm{~T}$ \\
\hline 40 & $\mathrm{ZrO}_{2}$ & 5.19 & 5.24 & 5.38 & 90 & 99.2 & 90 & 40.0 & 5.04 & 5.36 & $\mathrm{~T}$ \\
\hline
\end{tabular}

${ }^{a} \mathrm{~T}$ : training set; $\mathrm{V}$ : validation set; $E_{\text {exp. }}$ : experimental gaps; $E_{\text {pred. }}$ : predicted gaps.

convenient for subsequent use. Fig. 2 was plotted to visualize the observed experimental $E_{\mathrm{g}}$ values $v s$. predicted values of $E_{\mathrm{g}}$ as calculated by eqn (6). The correlation coefficient $R^{2}$ and the $\mathrm{RMSE}_{\mathrm{E}}$ of the training set containing 30 values of band gaps of MONs are 0.848 and $0.378 \mathrm{eV}$, indicating an excellent goodnessof-fit. $Q_{\mathrm{EXT}}{ }^{2}$ and $\mathrm{RMSE}_{\mathrm{P}}$ are 0.814 and $0.408 \mathrm{eV}$ respectively, indicating good predictive ability. The developed model contains three principal components $(N: A=10: 1, N$ : number of data in training set, $A$ : number of principal components), which accounts for 85 percent explanation of the total variance. The physical meaning and the loading weights of the descriptors in the first two principal components are displayed in Table 2. In the first principal component, heat of formation, beta angle of unit cell and the Thomas Fermi vector outweigh the other descriptors. For the second principle component, Fermi energy, heat of formation and the ratio of metal atoms to oxygen atoms are the most significant descriptors. The VIP values of selected descriptors are plotted in Fig. 3. The VIPs of heat of formation, beta angle of unit cell and Thomas Fermi vector are larger than 1, indicating that these descriptors explain most of the variance of band gaps. Computed heat of formation was compared with the experimental ones in Table S4 and Fig. S1† to validate the acceptability of computed descriptors derived from small molecular model computation, which displayed acceptable fitting performance.

$$
\begin{aligned}
E_{\mathrm{g}}= & 0.553 H_{\mathrm{F}}+0.0806 B E T A+1.09 D^{-2}-0.0121 V_{2}+0.18 E_{\mathrm{Fermi}} \\
& -2.23 T F W+0.803 R+0.00469 E_{\mathrm{T}}-0.000305 D E N C \\
& -0.00403 X C E N C+0.168
\end{aligned}
$$

$N=30, A=3, R^{2}=0.848, \mathrm{RMSE}_{\mathrm{E}}=0.378 \mathrm{eV}, \mathrm{RMSE}_{\mathrm{CV}}=$ $0.478 \mathrm{eV}, Q_{\mathrm{EXT}}{ }^{2}=0.814, \mathrm{RMSE}_{\mathrm{P}}=0.408 \mathrm{eV}$.

The applicability domain of the developed model was determined by the reported method mentioned above. Data points from 

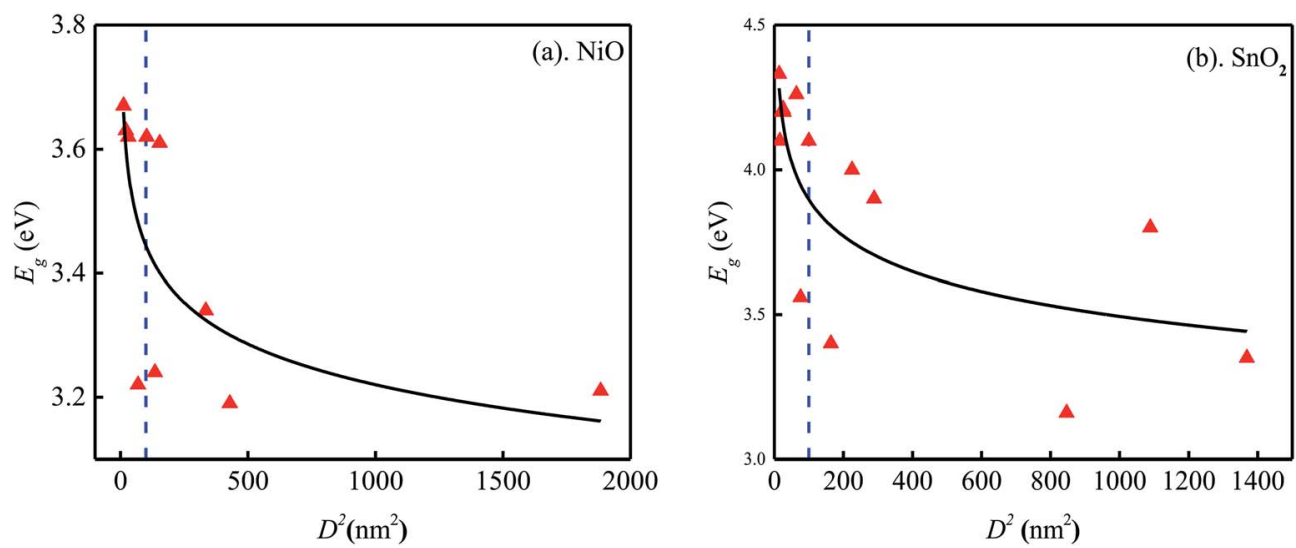

Fig. 1 (a) Band gaps of $\mathrm{NiO}$ versus the squared diameter of the particles. (b) Band gaps of $\mathrm{SnO}_{2}$ versus the squared diameter of the particles. The dotted line marks the value of $100 \mathrm{~nm}^{2}$, which means that data points in the zone left to the dotted line refers to particles with a size smaller than $10 \mathrm{~nm}$ and the other data points relate to particles that are larger than $10 \mathrm{~nm}$.

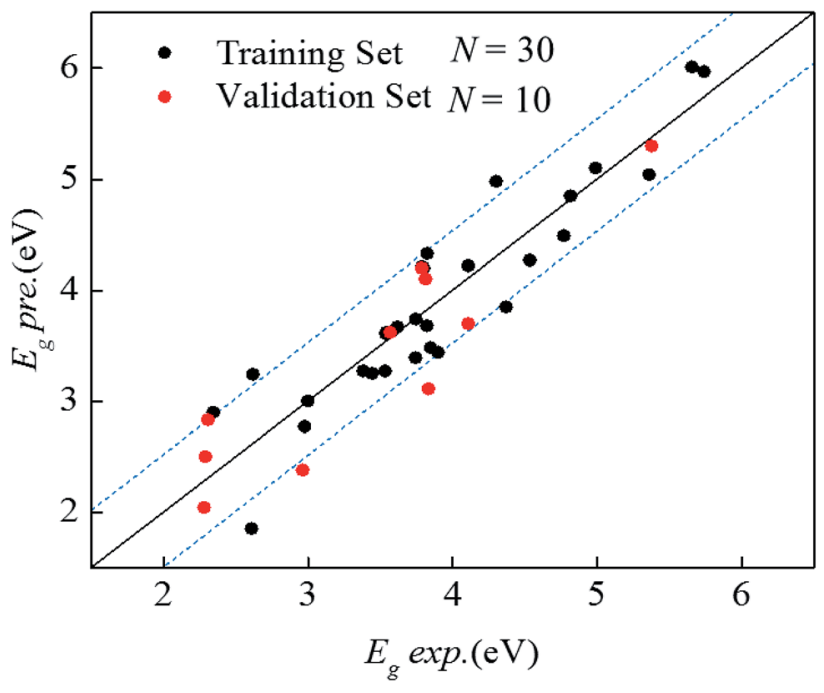

Fig. 2 Observed vs. predicted $E_{g}$ values.

both training set and validation set were investigated. The detailed information of the calculation process is provided in Table S2. $\dagger$ There are 5 and 4 data points with at least one outlier of descriptor in the training set and the validation set respectively. But there is only one material $\left(\mathrm{Y}_{2} \mathrm{O}_{3}\right.$ in validation set) that was judged as an outlier, mainly because its heat of formation deviates far from that of most metal oxides in this model.

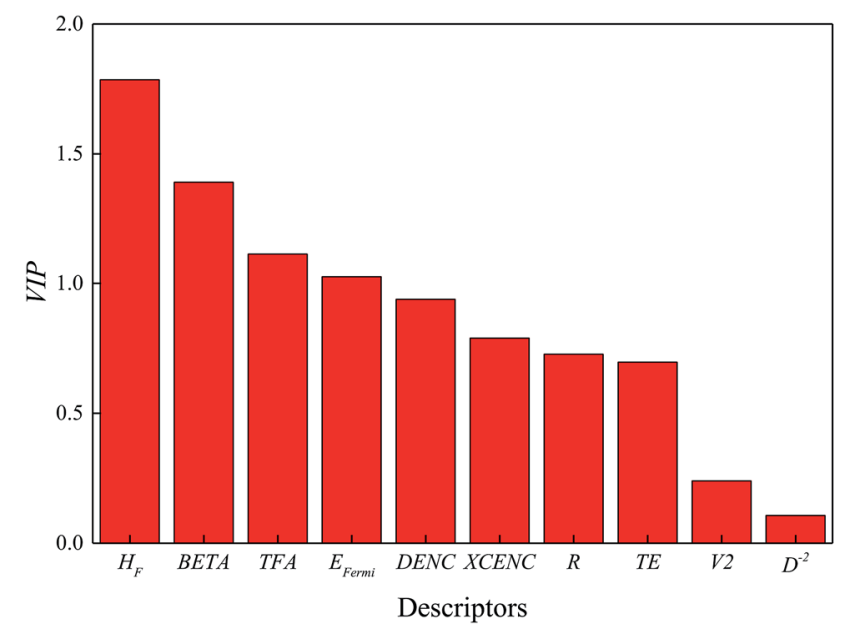

Fig. 3 Variable influence for the projection (VIP) plot of selected descriptors.

Table 2 Meaning and loading weight of descriptors in the QSPR model ${ }^{a}$

\begin{tabular}{|c|c|c|c|c|}
\hline$H_{\mathrm{F}}$ & Heat of formation & MOPAC & 0.65 & 0.57 \\
\hline BETA & Beta angle of unit cell & - & 0.51 & 0.34 \\
\hline$V_{2}$ & Length of second vector of unit cell & VASP & -0.06 & -0.12 \\
\hline$E_{\text {Fermi }}$ & Energy of Fermi level & VASP & 0.03 & 0.72 \\
\hline$T F W$ & Thomas Fermi vector & VASP & -0.35 & 0.14 \\
\hline$D E N C$ & Electron-electron repulsion energy & VASP & 0.28 & -0.04 \\
\hline XCENC & Exchange and correlation energy & VASP & -0.20 & 0.14 \\
\hline
\end{tabular}

${ }^{a} \mathrm{w}^{*} \mathrm{c}[1]$ : loading weight of component [1] $\mathrm{w}^{*} \mathrm{c}$ [2]: loading weight of component [2]. 
Table 3 Predictive performance of the developed model vs. empirical equation

\begin{tabular}{llll}
\hline Predictive method & $R^{2}$ & $R M S E(\mathrm{eV})$ & Reference \\
\hline QSPR model & 0.848 & 0.378 & This study \\
Empirical equation based on computed heat of formation & 0.490 & 2.24 & Portier et al., 2001 \\
Empirical equation based on experimental heat of formation & 0.571 & 1.58 & Portier et al., 2001
\end{tabular}

\subsection{Mechanistic interpretation}

Heat of formation and beta angle of unit cell are the most significant descriptors. The correlation between band gap and heat of formation has already been demonstrated by previous studies, that is: bulk metal oxides with larger heat of formation tend to have a larger band gap. ${ }^{68-70}$ In this study, this correlation for metal oxide nanoparticles was also observed $(p<0.001)$, which means that this relation remains irrespective of a decrease of material size. It needs to be notified that in this study, heat of formation was calculated by MOPAC PM7. This calculation may not be as accurate as experimental determination but provides a quick method for obtaining heat of formation. Crystalline types could be reflected by not only direct variables characterizing crystalline type such as beta angle and length of vector but also by indirect variables like the E-Fermi and the Thomas Fermi vector because these parameters were calculated based on specific crystalline types. The presence of the beta angle $(p<0.05)$ and the length of unit cell in the developed model indicates that crystalline type is an important parameter influencing the band gap of MONs. Beta angle and length of vector contribute to the interference of the wave vector of electrons and consequently determine the density of electrons and eventually influence band gaps.

The VIP of materials size is not large, which coincides with the Brus equation and the computed standard deviation of materials with multiple sizes. Although the effect of size has been taken into consideration during data pre-processing, it needs to be noted that some variables which may influence the band gap of MONs, were not contained in the developed model. For example, the annealing temperature, time and the ratio of different precursor materials might also affect the value of the band gap. However, these variables are difficult to describe because of the numerous types of MONs and numerous methods to synthesize nanoparticles. Different experimental conditions may lead to unknown differences in the composition of materials, which need to be characterized further.

\subsection{Model comparison}

The developed QSPR model was compared with empirical equation. Band gaps were calculated with the computed and experimental heat of formation according to the empirical equations. ${ }^{11}$ The results of comparison are shown in Table 3.

The empirical equation using experimental heat of formation to predict band gap, shows better performance than the empirical equation which used computed heat of formation. However, $R^{2}$ did not change significantly while there was a decrease in RMSE. During characterization the performance of these two empirical methods, it is found that these two methods underestimate or overestimate band gaps. Our QSPR model developed by PLS performs better than previous empirical equations.

\section{Conclusions}

A nano-QSPR model, covering various crystalline types and material sizes, was developed to predict band gaps for metal oxide nanoparticles. The established QSPR model performs well in terms of goodness-of-fit, robustness and predictive ability. Heat of formation and the beta angle of unit cell are the most important parameters influencing the band gaps of metal oxide nanoparticles. Compared with empirical equation related to the heat of formation, the developed QSPR model had a larger value of $R^{2}$ and a smaller RMSE. This newly developed QSPR model could thus contribute significantly to the rapid screening of the ecological risk of existing MONs and could assist the design of novel MONs that are environmentally safe.

\section{Conflicts of interest}

The author declares no competing financial interest.

\section{Acknowledgements}

This study was supported by The National Key Research and Development Program (2017YFD020030603) of China and the National Natural Science Foundation $(21477016,21777019)$ of China.

\section{References}

1 Y. Pan, T. Li, J. Cheng, D. Telesca, J. I. Zink and J. Jiang, Nano-QSAR modeling for predicting the cytotoxicity of metal oxide nanoparticles using novel descriptors, $R S C$ Adv., 2016, 6(31), 25766-25775.

$2 \mathrm{H}$. J. Eom and J. Choi, Oxidative stress of $\mathrm{CeO}_{2}$ nanoparticles via p38-Nrf-2 signaling pathway in human bronchial epithelial cell, Beas-2B, Toxicol. Lett., 2009, 187(2), 77-83.

3 H. Zhang, Z. Ji, T. Xia, H. Meng, C. Low-Kam, R. Liu, S. Pokhrel, S. Lin, X. Wang, Y. P. Liao and M. Wang, Use of metal oxide nanoparticle band gap to develop a predictive paradigm for oxidative stress and acute pulmonary inflammation, ACS Nano, 2012, 6(5), 4349-4368.

4 R. Liu, H. Y. Zhang, Z. X. Ji, R. Rallo, T. Xia, C. H. Chang, A. Nel and Y. Cohen, Development of structure-activity relationship for metal oxide nanoparticles, Nanoscale, 2013, 5(12), 5644-5653. 
5 C. Kaweeteerawat, A. Ivask, R. Liu, H. Zhang, C. H. Chang, C. Low-Kam, H. Fischer, Z. Ji, S. Pokhrel, Y. Cohen and D. Telesca, Toxicity of metal oxide nanoparticles in Escherichia coli correlates with conduction band and hydration energies, Environ. Sci. Technol., 2015, 49(2), 1105-1112.

$6 \mathrm{Y}$. Xu and M. A. Schoonen, The absolute energy positions of conduction and valence bands of selected semiconducting minerals, Am. Mineral., 2000, 85(3-4), 543-556.

7 J. Portier, G. Campet, A. Poquet, C. Marcel and M. A. Subramanian, Degenerate semiconductors in the light of electronegativity and chemical hardness, Int. J. Inorg. Mater., 2001, 3(7), 1039-1043.

8 K. T. Selvi, K. A. Mangai, M. Priya, M. Rathnakumari and P. S. Kumar, Effect of solvent and annealed temperature on band gap energies of $\mathrm{MgO}$ nanoparticles, in 2014 International Conference on Science Engineering and Management Research (ICSEMR), IEEE, 2014, pp. 1-6.

9 C. S. Wang and W. E. Pickett, Density-functional theory of excitation spectra of semiconductors: application to $\mathrm{Si}$, Phys. Rev. Lett., 1983, 51(7), 597.

10 K. Jagiello, B. Chomicz, A. Avramopoulos, A. Gajewicz, A. Mikolajczyk, P. Bonifassi, M. G. Papadopoulos, J. Leszczynski and T. Puzyn, Size-dependent electronic properties of nanomaterials: how this novel class of nanodescriptors supposed to be calculated?, Struct. Chem., 2017, 28(3), 635-643.

11 J. Portier, G. Campet, C. W. Kwon, J. Etourneau and M. A. Subramanian, Relationships between optical band gap and thermodynamic properties of binary oxides, Int. J. Inorg. Mater., 2001, 3(7), 1091-1094.

12 G. P. Moss, J. C. Dearden, H. Patel and M. T. Cronin, Quantitative structure-permeability relationships (QSPRs) for percutaneous absorption, Toxicol. In Vitro, 2002, 16(3), 299-317.

13 Y. Shao, J. Liu, M. Wang, L. Shi, X. Yao and P. Gramatica, Integrated QSPR models to predict the soil sorption coefficient for a large diverse set of compounds by using different modeling methods, Atmos. Environ., 2014, 88, 212-218.

14 T. Puzyn, B. Rasulev, A. Gajewicz, X. Hu, T. P. Dasari, A. Michalkova, H. M. Hwang, A. Toropov, D. Leszczynska and J. Leszczynski, Using nano-QSAR to predict the cytotoxicity of metal oxide nanoparticles, Nat. Nanotechnol., 2011, 6(3), 175.

15 S. Kar, A. Gajewicz, T. Puzyn and K. Roy, Nano-quantitative structure-activity relationship modeling using easily computable and interpretable descriptors for uptake of magnetofluorescent engineered nanoparticles in pancreatic cancer cells, Toxicol. In Vitro, 2014, 28(4), 600-606.

16 K. Pathakoti, M. J. Huang, J. D. Watts, X. He and H. M. Hwang, Using experimental data of Escherichia coli to develop a QSAR model for predicting the photo-induced cytotoxicity of metal oxide nanoparticles, J. Photochem. Photobiol., B, 2014, 130, 234-240.

17 S. Kar, A. Gajewicz, K. Roy, J. Leszczynski and T. Puzyn, Extrapolating between toxicity endpoints of metal oxide nanoparticles: Predicting toxicity to Escherichia coli and human keratinocyte cell line (HaCaT) with Nano-QTTR, Ecotoxicol. Environ. Saf., 2016, 126, 238-244.

18 E. Wyrzykowska, A. Mikolajczyk, C. Sikorska and T. Puzyn, Development of a novel in silico model of zeta potential for metal oxide nanoparticles: a nano-QSPR approach, Nanotechnology, 2016, 27(44), 445702.

19 R. Bharthasaradhi and L. C. Nehru, Structural and phase transition of $\alpha-\mathrm{Al}_{2} \mathrm{O}_{3}$ powders obtained by co-precipitation method, Phase Transitions, 2016, 89(1), 77-83.

20 R. Bharthasaradhi and L. C. Nehru, Preparation and characterisation of nanoscale $\alpha-\mathrm{Al}_{2} \mathrm{O}_{3}$ by precipitation method, American Institute of Physics Conference Series. AIP Publishing LLC, 2015.

21 A. A. Ansari, J. Labis, M. Alam, S. M. Ramay, N. Ahmad and A. Mahmood, Influence of copper ion doping on structural, optical and redox properties of $\mathrm{CeO}_{2}$ nanoparticles, $J$. Electroceram., 2016, 36(1-4), 150-157.

22 K. Anandan and V. Rajendran, Sheet, spherical and platelike chromium sesquioxide $\left(\mathrm{Cr}_{2} \mathrm{O}_{3}\right)$ nanostructures synthesized via ionic surfactants assisted facile precipitation method, Mater. Lett., 2015, 146, 99-102.

23 K. Anandan and V. Rajendran, Studies on structural, morphological, magnetic and optical properties of chromium sesquioxide $\left(\mathrm{Cr}_{2} \mathrm{O}_{3}\right)$ nanoparticles: synthesized via facile solvothermal process by different solvents, Mater. Sci. Semicond. Process., 2014, 19, 136-144.

24 B. Balamurugan, I. Aruna, B. R. Mehta and S. M. Shivaprasad, Size-dependent conductivity-type inversion in $\mathrm{Cu}_{2} \mathrm{O}$ nanoparticles, Phys. Rev. B, 2004, 69(16), 165419.

25 M. Srivastava, J. Singh, R. K. Mishra and A. K. Ojha, Electrooptical and magnetic properties of monodispersed colloidal $\mathrm{Cu}_{2} \mathrm{O}$ nanoparticles, J. Alloys Compd., 2013, 555, 123-130.

26 X. Zhang, Y. Niu, Y. Li, X. Hou, Y. Wang, R. Bai and J. Zhao, Synthesis, optical and magnetic properties of $\alpha-\mathrm{Fe}_{2} \mathrm{O}_{3}$ nanoparticles with various shapes, Mater. Lett., 2013, 99, 111-114.

27 G. Sinha, D. Ganguli and S. Chaudhuri, $\mathrm{Ga}_{2} \mathrm{O}_{3}$ and $\mathrm{GaN}$ nanocrystalline film: reverse micelle assisted solvothermal synthesis and characterization, J. Colloid Interface Sci., 2008, 319(1), 123-129.

28 D. Shiojiri, D. Fukuda, R. Yamauchi, N. Tsuchimine, K. Koyama, S. Kaneko, A. Matsuda and M. Yoshimoto, Room-temperature laser annealing for solid-phase epitaxial crystallization of $\beta-\mathrm{Ga}_{2} \mathrm{O}_{3}$ thin films, Appl. Phys. Express, 2016, 9(10), 105502.

29 B. Zhao, X. Li, L. Yang, F. Wang, J. Li, W. Xia, W. Li, L. Zhou and C. Zhao, $\mathrm{B}_{-} \mathrm{Ga}_{2} \mathrm{O}_{3}$ Nanorod Synthesis with a One-step Microwave Irradiation Hydrothermal Method and its Efficient Photocatalytic Degradation for Perfluorooctanoic Acid, Photochem. Photobiol., 2015, 91(1), 42-47.

30 S. K. Tripathi, C. Kaur and R. Kaur, Effect of calcination temperature on phase transformation of $\mathrm{HfO}_{2}$ nanoparticles, AIP Publishing, 2015.

31 C. Latha, M. Raghasudha, Y. Aparna, D. Ravinder, P. Veerasomaiah and D. Shridhar, Effect of capping agent 
on the morphology, size and optical properties of $\operatorname{In}_{2} \mathrm{O}_{3}$ nanoparticles, Mater. Res., 2017, 20(1), 256-263.

32 M. A. Farrukh, F. Imran, S. Ali, M. Khaleeq-ur-Rahman and I. I. Naqvi, Micelle assisted synthesis of $\mathrm{La}_{2} \mathrm{O}_{3}$ nanoparticles and their applications in photodegradation of bromophenol blue, Russ. J. Appl. Chem., 2015, 88(9), 1523-1527.

33 G. A. Bagheri, M. Sabbaghan and Z. Mirgani, A comparative study on properties of synthesized $\mathrm{MgO}$ with different templates, Spectrochim. Acta, Part A, 2015, 137, 1286-1291.

34 S. Gnanam and V. Rajendran, Synthesis of $\mathrm{CeO}_{2}$ or $\alpha-\mathrm{Mn}_{2} \mathrm{O}_{3}$ nanoparticles via sol-gel process and their optical properties, J. Sol-Gel Sci. Technol., 2011, 58(1), 62-69.

35 W. J. Duan, S. H. Lu, Z. L. Wu and Y. S. Wang, Size effects on properties of NiO nanoparticles grown in alkali salts, J. Phys. Chem. C, 2012, 116(49), 26043-26051.

36 A. Tang, X. Li, Z. Zhou, J. Ouyang and H. Yang, Mechanochemical synthesis of $\mathrm{Ni}(\mathrm{OH})_{2}$ and the decomposition to NiO nanoparticles: thermodynamic and optical spectra, J. Alloys Compd., 2014, 600, 204-209.

37 A. Muthuvinayagam, N. Melikechi, P. D. Christy and P. Sagayaraj, Investigation on mild condition preparation and quantum confinement effects in semiconductor nanocrystals of $\mathrm{SnO}_{2}$, Phys. B, 2010, 405(4), 1067-1070.

38 S. Begum, T. B. Devi and M. Ahmaruzzaman, L-lysine monohydrate mediated facile and environment friendly synthesis of $\mathrm{SnO}_{2}$ nanoparticles and their prospective applications as a catalyst for the reduction and photodegradation of aromatic compounds, J. Environ. Chem. Eng., 2016, 4(3), 2976-2989.

39 A. Bhattacharjee, M. Ahmaruzzaman and T. Sinha, A novel approach for the synthesis of $\mathrm{SnO}_{2}$ nanoparticles and its application as a catalyst in the reduction and photodegradation of organic compounds, Spectrochim. Acta, Part A, 2015, 136, 751-760.

40 Y. He, P. Tang, J. Li, J. Zhang, F. Fan and D. Li, Ultrafast response and recovery ethanol sensor based on $\mathrm{SnO}_{2}$ quantum dots, Mater. Lett., 2016, 165, 50-54.

41 W. B. Soltan, M. Mbarki, R. Bargougui, S. Ammar, O. Babot and T. Toupance, Effect of hydrolysis ratio on structural, optical and electrical properties of $\mathrm{SnO}_{2}$ nanoparticles synthesized by polyol method, Opt. Mater., 2016, 58, 142150.

42 V. Senthilkumar, P. Vickraman, M. Jayachandran and C. Sanjeeviraja, Synthesis and characterization of $\mathrm{SnO}_{2}$ nanopowder prepared by precipitation method, $J$. Dispersion Sci. Technol., 2010, 31(9), 1178-1181.

43 S. Naghibi, M. A. F. Sani and H. R. M. Hosseini, Application of the statistical Taguchi method to optimize $\mathrm{TiO}_{2}$ nanoparticles synthesis by the hydrothermal assisted solgel technique, Ceram. Int., 2014, 40(3), 4193-4201.

44 Ü. Ö. A. Arıer and F. Z. Tepehan, Controlling the particle size of nanobrookite $\mathrm{TiO}_{2}$ thin films, J. Alloys Compd., 2011, 509(32), 8262-8267.

45 J. G. Li, T. Ishigaki and X. Sun, Anatase, brookite, and rutile nanocrystals via redox reactions under mild hydrothermal conditions: phase-selective synthesis and physicochemical properties, J. Phys. Chem. C, 2007, 111(13), 4969-4976.

46 P. Sivakarthik, V. Thangaraj and M. Parthibavarman, A facile and one-pot synthesis of pure and transition metals $(\mathrm{M}=\mathrm{Co}$ \& Ni) doped $\mathrm{WO}_{3}$ nanoparticles for enhanced photocatalytic performance, J. Mater. Sci.: Mater. Electron., 2017, 28(8), 5990-5996.

47 G. Bhavani and S. Ganesan, Structural, Morphological and Optical Study of Bismuth and Zinc Co-Doped Yttrium Oxide Prepared by Solvothermal and Wet Chemical Method, Acta Phys. Pol., A, 2016, 130(6), 1373-1379.

48 L. Jing, X. Sun, D. Zheng, Y. Xu, W. Li and W. Cai, Quantum size effect and photocatalytic properties of $\mathrm{ZnO}$ ultrafine particles, J. Harbin Inst. Technol., 2001, 33, 345-348.

49 R. Nasser, W. B. H. Othmen, H. Elhouichet and M. Férid, Preparation, characterization of Sb-doped $\mathrm{ZnO}$ nanocrystals and their excellent solar light driven photocatalytic activity, Appl. Surf. Sci., 2017, 393, 486-495.

50 S. Klubnuan, P. Amornpitoksuk and S. Suwanboon, Structural, optical and photocatalytic properties of $\mathrm{MgO} /$ $\mathrm{ZnO}$ nanocomposites prepared by a hydrothermal method, Mater. Sci. Semicond. Process., 2015, 39, 515-520.

51 P. Kubelka and F. Munk, An article on optics of paint layers, Z. Tech. Phys., 1931, 12, 593-601.

52 L. E. Brus, A simple model for the ionization potential, electron affinity, and aqueous redox potentials of small semiconductor crystallites, J. Chem. Phys., 1983, 79(11), 5566-5571.

53 V. I. Klimov, A. A. Mikhailovsky, S. Xu, A. Malko, J. A. Hollingsworth, A. C. Leatherdale, H. J. Eisler and M. G. Bawendi, Optical gain and stimulated emission in nanocrystal quantum dots, Science, 2000, 290(5490), 314317.

54 G. Kresse and J. Furthmüller, Software vasp, Vienna, 1999.

55 J. J. Stewart, Stewart computational chemistry-MOPAC home page, 2016.

56 K. Tämm, L. Sikk, J. Burk, R. Rallo, S. Pokhrel, L. Mädler, J. J. Scott-Fordsmand, P. Burk and T. Tamm, Parametrization of nanoparticles: development of fullparticle nanodescriptors, Nanoscale, 2016, 8(36), 1624316250.

57 Jade, M. D. I. 2010. 9.5; Materials Data. Inc., Livermore, CA, USA.

58 FindIt, I. C. S. C. Inorganic Crystal Structure Database, 2009. 59 N. M. O'Boyle, M. Banck, C. A. James, C. Morley, T. Vandermeersch and G. R. Hutchison, Open Babel: an open chemical toolbox, J. Cheminf., 2011, 3(1), 33.

60 M. Bylesjö, M. Rantalainen, O. Cloarec, J. K. Nicholson, E. Holmes and J. Trygg, OPLS discriminant analysis: combining the strengths of PLS-DA and SIMCA classification, J. Chemom., 2006, 20(8-10), 341-351.

$61 \mathrm{H}$. Wold, Soft modeling: the basic design and some extensions, in Systems under Indirect Observation, 1982, vol. 2, p. 343.

62 S. Wold, A. Ruhe, H. Wold and W. J. Dunn III, The collinearity problem in linear regression. The partial least squares (PLS) approach to generalized inverses, SIAM 
Journal on Scientific and Statistical Computing, 1984, 5(3), 735-743.

63 S. Wold, M. Sjöström and L. Eriksson, PLS-regression: a basic tool of chemometrics, Chemom. Intell. Lab. Syst., 2001, 58(2), 109-130.

$64 \mathrm{R}$. C. Team, $R$ language definition, $\mathrm{R}$ Foundation for Statistical Computing, Vienna, Austria, 2000.

65 P. P. Roy and K. Roy, On some aspects of variable selection for partial least squares regression models, QSAR Comb. Sci., 2008, 27(3), 302-313.
66 OECD, Guidance document on the validation of (Quantitative) Structure-Activity Relationship [(Q)SAR] models, 2007.

67 K. Roy, S. Kar and P. Ambure, On a simple approach for determining applicability domain of QSAR models, Chemom. Intell. Lab. Syst., 2015, 145, 22-29.

68 R. G. Pearson, Recent advances in the concept of hard and soft acids and bases, J. Chem. Educ., 1987, 64(7), 561.

69 R. G. Pearson, Maximum chemical and physical hardness, J. Chem. Educ., 1999, 76(2), 267.

70 R. G. Parr and P. K. Chattaraj, Principle of maximum hardness, J. Am. Chem. Soc., 1991, 113(5), 1854-1855. 